\title{
Impact of placenta praevia on obstetric outcome
}

\author{
Neelam Meena $^{1 *}$, Anupama Dave ${ }^{1}$, Shivraj Meena ${ }^{2}$, Asha Meena ${ }^{3}$, Ankita Shrivastava ${ }^{1}$
}

\author{
${ }^{1}$ Department of Obstetrics \& Gynaecology, MGM Medical College, Indore, Madhya Pradesh, India \\ ${ }^{2}$ Department of Medicine, AIIMS, New Delhi, India \\ ${ }^{3}$ Department of Dental, AIIMS, New Delhi, India
}

Received: 20 November 2014

Accepted: 20 December 2014

\author{
*Correspondence: \\ Dr. Neelam Meena, \\ E-mail: dr.neeluck@gmail.com
}

Copyright: (C) the author(s), publisher and licensee Medip Academy. This is an open-access article distributed under the terms of the Creative Commons Attribution Non-Commercial License, which permits unrestricted non-commercial use, distribution, and reproduction in any medium, provided the original work is properly cited.

\section{ABSTRACT}

Background: Placenta praevia is the implantation of the placenta partially or totally in the lesser segment of the uterus. The blood loss is generally mild and frequent but at times can be enormous and life threatening. The frequency of placenta praevia is 3-5 per 1000 pregnancies thought out the world and is still increasing for the reason that of growing caesarean section rates. ${ }^{2}$ The present study was carried out to asses impact of placenta praevia on obstetric outcome at our setup.

Methods: This was case control study that was conducted at department of gynaecology and obstetrics, M Y hospital, M G M medical college, Indore from Sep 2011 to Feb 2013. A predesigned proforma was used to collect the study variables.

Results: The incidence of placenta previa was $0.76 \%$. Maximum patients belonged to age group of 21-30 years $(70.43 \%)$ and in gravidae $>2(35.65 \%)$. In this study $22.6 \%$ patients of $\mathrm{PPH}, 36.52 \%$ of perpueral sepsis, $1.75 \%$ of UTI, $4.35 \%$ of ARF, $5.22 \%$ of wound infection, $1.74 \%$ of DIC and $5.22 \%$ patients of placenta accrete. Caesarean hysterectomy and uterine artery ligation were done in $6.08 \%$ and $13.04 \%$ patients respectively. Hysterectomy was done in 4 patients belonging to anterior PP and 3 patients in posterior PP group. Major placenta praevia was present in $47.82 \%$ patients. $6 \%$ patients present in hospital with gestational age $<28$ weeks. Low birth weight $(<2.5 \mathrm{~kg})$ baby was $65.21 \%$. $2.86 \%$ patient of APH, $0.76 \%$ of PP, $1.40 \%$ of AP and $0.70 \%$ of UC.

Conclusions: It was concluded that increased maternal age and parity, history of previous caesarean section are identified risk factors which are same as reported in western literature. Sonographic determination of the placental position where its location be-Neath the uterine incision is very important to predict maternal outcomes in placenta praevia patients, and such cases, close attention should be paid for massive haemorrhage.

Keywords: Placenta praevia, Caesarean, Hysterectomy

\section{INTRODUCTION}

Placenta praevia is the implantation of the placenta partially or totally in the lesser segment of the uterus. Placenta praevia is categorized as minor or major placenta praevia. ${ }^{1}$ When internal os is covered or touched by placental edge it is termed as major placenta praevia. The blood loss is generally mild and frequent but at times can be enormous and life threatening. The frequency of placenta praevia is $3-5$ per 1000 pregnancies thought out the world and is still increasing for the reason that of growing caesarean section rates. ${ }^{2}$

The occurrence is greatly elevated at twenty weeks than at 36 weeks and above. As pregnancy move on the lower uterine segment is shaped; the upper segment broaden and move with the placenta. $^{3}$ the self-determining risk factor for placenta praevia is a previous caesarean section. The threat enhances with the increasing number of caesarean sections performed. The frequency is $2 \%$ 
after one previous caesarean section, $4.1 \%$ after two and it is $22 \%$ after three. ${ }^{1}$

Placenta praevia is associated with high parity, increasing maternal age, uterine abnormalities, smoking, previous (recurrence rate 4-8\%), caesarean section, termination of pregnancy and intrauterine surgery. ${ }^{4}$ Worldwide over 600000 women die annually in pregnancy and child birth, and globally maternal mortality ratio is estimated at $400 / 100000$ live births. ${ }^{9}$ The rational of our study was to evaluate the impact of placenta praevia on obstetric out come at MYH Hospital Indore.

\section{METHODS}

The present study is undertaken among patients admitted either as emergency or through routine admission in department of obstetrics and genecology, M Y hospital, M G M medical college, Indore.

This study was conducted from September 2011 to February 2013. Total deliveries were 15000 during this period. 115 diagnosed cases of placenta praevia was selected on the basis of sonography from outdoor patient, emergency and indoor patient.

Convenient sampling technique was used for selection of study cases.

\section{Inclusion criteria}

Pregnant women with $\geq 28$ weeks of gestation diagnosed as case of placenta praevia were included in this study.

\section{Exclusion criteria}

1. All pregnant women presenting with bleeding per vaginal before 28 weeks of gestation.

2. APH due to abruption placentae, vasapraevia or any other local cause.

3. Pregnancy complicating with other medical disorder like diabetes mellitus.

\section{Statistical analysis}

Data was statistically analysed using SPSS for windows version 10. Chi-squared test was used for comparing groups of data. A P value of $<0.05$ was taken to indicate statistical significance.

\section{RESULTS}

Total number of cases of placenta praevia was 115 out of 15000 deliveries. The incidence of placenta praevia was $0.76 \%$.

Placenta praevia was more in advanced age $(>40)$. majority of patients in this study belonged to age group of 21-30 years $(70.43 \%)$, which is further supported by the statistical analysis data $\left(\chi^{2}=9.51, \mathrm{P}=0.023\right)$. The incidence of placenta praevia was more in multi parity in above table, which is further supported by the statistical analysis data $\left(\chi^{2}=15.8, \mathrm{P}=0.001\right)$. The incidence of placenta praevia was more associated with history of previous caesarean section, which is further supported by the statistical analysis data $\left(\chi^{2}=6.04, \mathrm{P}=0.049\right)$. The incidence of placenta praevia was more in low education level in our study, which is further supported by the statistical analysis data $\left(\chi^{2}=6.69, \mathrm{P}=0.035\right)$ (Table 1$)$.

Table 1: Characteristic of women with placenta praevia and control.

\begin{tabular}{|c|c|c|c|c|}
\hline Variable & $\begin{array}{l}\text { Placenta } \\
\text { praevia } \\
(n=115)(\%)\end{array}$ & $\begin{array}{l}\text { Control } \\
(\mathrm{n}=15000) \\
(\%)\end{array}$ & $\begin{array}{l}P \\
\text { value }\end{array}$ & $\chi^{2}$ \\
\hline \multicolumn{5}{|c|}{ Maternal age } \\
\hline$<20$ & $1(0.86)$ & $1000(6.66)$ & \multirow{4}{*}{0.023} & \multirow{4}{*}{9.51} \\
\hline $21-30$ & $81(70.43)$ & $10915(72.76)$ & & \\
\hline $31-40$ & $29(25.217)$ & $2722(18.14)$ & & \\
\hline$>40$ & $4(3.478)$ & $363(2.42)$ & & \\
\hline \multicolumn{5}{|l|}{ Parity } \\
\hline 1 & $24(20.869)$ & $4300(28.66)$ & \multirow{4}{*}{0.001} & \multirow{4}{*}{15.8} \\
\hline 2 & $41(35.65)$ & $6400(42.66)$ & & \\
\hline 3 & $30(26.08)$ & $3000(20.00)$ & & \\
\hline$>4$ & $20(17.39)$ & $1300(8.66)$ & & \\
\hline \multicolumn{5}{|c|}{ Previous caesarean section } \\
\hline 0 & $96(83.478)$ & $12848(85.65)$ & \multirow{3}{*}{0.049} & \multirow{3}{*}{6.04} \\
\hline 1 & $13(11.30)$ & $1853(12.35)$ & & \\
\hline$>2$ & $6(5.21)$ & $299(1.99)$ & & \\
\hline \multicolumn{5}{|c|}{ Education } \\
\hline$<5$ & $58(50.43)$ & $6510(43.40)$ & \multirow{3}{*}{0.035} & \multirow{3}{*}{6.69} \\
\hline $6-10$ & $25(21.74)$ & $4968(33.12)$ & & \\
\hline$>10$ & $32(27.82)$ & $3522(23.48)$ & & \\
\hline
\end{tabular}

Maternal morbidity was commonly seen in older age group. 26 patients $(22.60 \%)$ developed postpartum haemorrhage, 7 cases (6\%) were ended up in obstetrical hysterectomy due to morbid adherent placenta praevia, they were grand multipara had history of previous caesarean section, 42 patients $(36.52 \%)$ patients developed puerperal sepsis, $1.74 \%$ developed DIC, $4.35 \%$ developed acute renal failure, wound infection in $(5.22 \%)$ (Table 2$)$.

Blood transfusion in $(96.52 \%)$, uterine A ligation in $13.04 \%$ and Urinary tract infection was observed in $1.74 \%$ (Table 2).

Anterior placenta praevia had increased risk of bleeding and required more blood transfusion than posterior. High incidence of placenta accrete $(10.34 \%)$ in anterior lying placenta praevia than posterior $(3.48 \%)$ but in this study statically not significance $(\mathrm{P}=0.180)$ (Table 3$)$.

High incidence of hysterectomy $(13.79 \%)$ in anterior lying placenta praevia than posterior $(3.48 \%)$ but in this study statically not significance $(P=0.065)$. High 
incidence of mortality $(6.89 \%)$ in anterior lying placenta praevia than posterior $(0.00 \%)$. which is further supported by the statistical analysis data $\left(\chi^{2}=5.64, \mathrm{P}=\right.$ 0.018) (Table 3).

Table 2: Maternal morbidity or outcome in placenta praevia.

\begin{tabular}{|lll|}
\hline Maternal morbidity & $\begin{array}{l}\text { No. of } \\
\text { cases }\end{array}$ & $\%$ \\
\hline PPH & 26 & 22.60 \\
\hline Puerperal sepsis & 42 & 36.52 \\
\hline UTI & 2 & 1.74 \\
\hline ARF & 5 & 4.35 \\
\hline Wound infection & 6 & 5.22 \\
\hline Blood transfusion & 111 & 96.52 \\
\hline Caesarean hysterectomy & 7 & 6.08 \\
\hline DIC & 2 & 1.74 \\
\hline Uterine A ligation & 15 & 13.04 \\
\hline Placenta accrete & 6 & 5.22 \\
\hline
\end{tabular}

Table 3: Univariate analysis of maternal pregnancy outcome according to placental position in placenta praevia.

\begin{tabular}{|clll|}
\hline & $\begin{array}{l}\text { Anterior } \\
\text { placenta } \\
\text { previa } \\
(\mathrm{n}=29)\end{array}$ & $\begin{array}{l}\text { Posterior } \\
\text { placenta } \\
\text { previa } \\
(\mathrm{n}=86)\end{array}$ & Significance \\
\hline Blood transfusion & & & \\
\hline $0-1$ & 4 & 36 & $\chi^{2}=8.7$ \\
\hline $2-3$ & 18 & 41 & $\mathrm{P}=0.013$ \\
\hline$>4$ & 7 & 9 & $\begin{array}{l}\chi^{2}=1.80 \\
\mathrm{P}=0.180\end{array}$ \\
\hline Placenta accrete & $3(10.34)$ & $3(3.48)$ & $\begin{array}{l}\chi^{2}=3.41 \\
\mathrm{P}=0.065\end{array}$ \\
\cline { 1 - 3 } Hysterectomy & $4(13.79)$ & $3(3.48)$ & $\begin{array}{l}\chi^{2}=5.64 \\
\mathrm{P}=0.018\end{array}$ \\
\hline Mortality & $2(6.89)$ & 0 &
\end{tabular}

Perinatal mortality are more common with gestational age $<28$ weeks $(71.42 \%)$ as compared with gestational age $>36$ weeks $(15.76 \%)$ in placenta praevia. which is further supported by the statistical analysis data $\left(\chi^{2}=\right.$ 29.4, $\mathrm{P}=0.001$ ) (Table 4).

Perinatal mortality in placenta praevia are more common in low birth weight baby $2.5 \mathrm{~kg}(45.33 \%)$ as compared with normal birth weight $>2.5 \mathrm{~kg}(12.50 \%)$ which is further supported by the statistical analysis data $\left(\chi^{2}=\right.$ $12.5, \mathrm{P}=0.001)$ (Table 4).

Pregnant women with male babies carry a higher risk of placenta praevia which is further supported by the statistical analysis data $\left(\chi^{2}=3.56, \mathrm{P}=0.05\right)$. Perinatal mortality in placenta praevia is not dependent on mode of delivery (Table 4).
Table 4: Perinatal outcome in placenta praevia $\&$ its significance.

\begin{tabular}{|c|c|c|c|c|}
\hline Variable & $\begin{array}{l}\text { No. of } \\
\text { cases } \\
(\%)\end{array}$ & $\begin{array}{l}\text { Take baby } \\
\text { to home } \\
(\%)\end{array}$ & $\begin{array}{l}\text { No. of } \\
\text { PND }(\%)\end{array}$ & P value \\
\hline \multicolumn{5}{|c|}{ Mode of del } \\
\hline C-section & 108 & $75(69.44)$ & $33(30.55)$ & \multirow{2}{*}{$\begin{array}{l}\mathrm{P}=0.144 \\
\chi^{2}=2.13\end{array}$} \\
\hline Normal del & 7 & $3(42.85)$ & $4(57.14)$ & \\
\hline \multicolumn{5}{|c|}{ Placenta praevia } \\
\hline Minor & 61 & $41(67.21)$ & $20(32.78)$ & \multirow{2}{*}{$\begin{array}{l}\chi^{2}=0.73 \\
P=0.786\end{array}$} \\
\hline Major & 54 & $35(64.81)$ & $19(35.18)$ & \\
\hline \multicolumn{5}{|c|}{ Gestational age (weeks) } \\
\hline$<28$ & 7 & $2(28.57)$ & $5(71.42)$ & \multirow{4}{*}{$\begin{array}{l}\chi^{2}=29.4 \\
P=0.001\end{array}$} \\
\hline $28-32$ & 24 & $7(29.16)$ & $17(70.83)$ & \\
\hline $33-36$ & 46 & $37(80.43)$ & $9(19.56)$ & \\
\hline$>36$ & 38 & $32(84.21)$ & $6(15.78)$ & \\
\hline \multicolumn{5}{|c|}{ Body weight (kg) } \\
\hline$<2.5$ & 75 & $41(54.66)$ & $34(45.33)$ & \multirow{2}{*}{$\begin{array}{l}\chi^{2}=12.5 \\
P=0.001\end{array}$} \\
\hline$>2.5$ & 40 & $35(87.50)$ & $5(12.50)$ & \\
\hline \multicolumn{5}{|c|}{ Sex of baby } \\
\hline Male & 67 & $49(73.13)$ & $18(26.86)$ & \multirow{2}{*}{$\begin{array}{l}\chi^{2}=3.56 \\
P=0.05\end{array}$} \\
\hline Female & 48 & $27(56.25)$ & $21(43.75)$ & \\
\hline
\end{tabular}

\section{DISCUSSION}

In this study of placenta praevia from various aspects we evaluated this fascinating obstetric problem keeping in mind to search out the facts and factors that can help us to improve the maternal and perinatal prognosis. Total sample size was 15000 in which 115 cases of placenta praevia was present. The incidence of placenta praevia in our study was $0.76 \%$ (1/130 pregnancy). Bahar A et al. ${ }^{7}$ showed similar trend of incidence $(0.73)$.

\section{Age}

Present study revealed that placenta praevia was more in advanced age $(>30)$. Majority of patients in this study belonged to age group of 21-30 years probably early age of marriage is responsible for this lower age incidence in our country. Similar trends of placenta praevia according to maternal age were present in study by Tai Ho Hung et al., ${ }^{6}$ Rabia et al. ${ }^{7}$ It was observed that increasing age has a strong relationship with placenta praevia. farkhunda Khursheed et al. ${ }^{8}$ have suggested that there is a strong relationship of increasing age with placenta praevia and a decreased frequency in women of 20-30 years of age group. In this study increasing age was shown to have influence to placenta praevia. As women age, collagen gradually swap normal muscle in walls of myometrial arteries, the atrophic changes that take place in older women may possibly also result in defective vascularisation of the decidua. Collectively under perfusion and under vascularisation have been suggested to participate in the progress of placenta praevia, as implantation has a tendency to take place in well vascularised arteries. 


\section{Parity}

This series shows that placenta praevia is commonly seen in grand multiparous women, and same has been reported by Nyango $\mathrm{DD}^{9}$ in a recently conducted study in Nigeria. Babinszki et al. has reported the incidence of $0.8 \%$ and $2.2 \%$ in multiparous and grand multiparous women respectively. In our study, placenta praevia was more common in multiparous.

\section{Caesarean section}

Caesarean section is one of most commonly performed obstetrical procedure. It is suggested that scar provides a nest for placental implantation in lower segment of uterus. Farkhunda Khursheed et al. ${ }^{8}$ has reported that patients with previous caesarean section are more prone to develop placenta praevia.

\section{Education}

This study revealed that the incidence was high among low educational group. Due to change in the attitude of general population. Similar result also found in Surraya Halimi et al. ${ }^{10}$

\section{Maternal morbidity}

Maternal morbidity was commonly seen in older age group. In this study 26 patients $(22.60 \%)$ developed postpartum haemorrhage, 7 cases $(6 \%)$ were ended up in obstetrical hysterectomy due to morbid adherent placenta praevia, they were grand multipara had history of previous caesarean section, 42 patients $(36.52 \%)$ patients developed puerperal sepsis, $1.74 \%$ developed DIC, $4.35 \%$ developed acute renal failure, wound infection in $(5.22 \%)$. Blood transfusion in $(96.52 \%)$, uterine a ligation in $13.04 \%$ and Urinary tract infection was observed in $1.74 \%$. Similar result found in by Shabnam Naz et al. ${ }^{11}$

\section{Position of placenta praevia}

In this study that maternal morbidities significantly increase when placenta is located in the anterior portion of uterus in placenta praevia. We strongly believe that the high incidence of anterior praevia among high parity especially 2 or more prior caesarean section in this study is associated with placental accreta. And it was observed that the incidence of placental accreta and hysterectomy is more common in anterior group. It is well known that Placenta accreta is accompanied with approximately $7 \sim 10 \%$ of all cases of placenta praevia, and in such cases, the chances of massive haemorrhage and hysterectomy are high. This study also support by Dong Gyu Jang et al. ${ }^{12}$

\section{Perinatal mortality}

In this study perinatal mortality are more common with gestational age $<28$ weeks $(71.42 \%)$ as compared with gestational age $>36$ weeks $(15.76 \%)$ in placenta praevia. which is further supported by Rabia Raheel et al. ${ }^{7}$
Perinatal mortality in placenta praevia are more common in low birth weight baby $2.5 \mathrm{~kg}(45.33 \%)$ as compared with normal birth weight $>2.5 \mathrm{~kg}(12.50 \%)$ which is further supported by the statistical analysis data in this study and also supported by Rabia Raheel et al. ${ }^{14}$

\section{Sex of baby}

Pregnant women with male babies carries a higher risk of placenta praevia, which is further supported by the statistical analysis data but by $\mathrm{S}$. W. Wen et al. ${ }^{13}$ suggest that pregnant women with male babies carry a higher risk of placenta praevia.

\section{CONCLUSION}

In cases of placenta praevia, perinatal mortality is high. Factors increasing lost of babies are lack of antenatal care, prematurity and low birth weight.

\section{Recommendation}

We strongly recommend antenatal care for every pregnant women and delivery of women having placenta praevia should be conducted at the hospitals having facilities of neonatal intensive care unit.

Funding: No funding sources

Conflict of interest: None declared

Ethical approval: The study was approved by the institutional ethics committee

\section{REFERENCES}

1. Kiondo P, Wandabwa J, Doyle P. Risk factors for placenta praevia presenting with severe vaginal bleeding in Mulago hospital, Kampala, Uganda. Afr Health Sci. 2008 Mar;8(1):44-9.

2. Madan I, Romero R, Kusanovic JP, Mittal P, Chaiworapongsa $T$, Dong Z, et al. The frequency and clinical significance of intraamniotic infection and/or inflammation in women with placenta praevia and vaginal bleeding: an unexpected observation. J Perinat Med. 2010 May;38(3):275-9.

3. Boyle RK, Waters BA, O'Rourke PK. Blood transfusion for caesarean delivery complicated by placenta praevia. Aust N Z J Obstet Gynaecol. 2009 Dec;49(6):627-30

4. Sinha P, Kuruba N. Ante-partum haemorrhage: an update. J Obstet Gynaecol. 2008;28:377-81.

5. Bahar A, Abusham A, Eskandar M, Sobande A, Alsunaidi M. Risk factors and pregnancy outcome in different types of placenta praevia. J Obstet Gynaecol Can. 2009;31(2):126-31.

6. Tai-Ho Hung, Ching-Chang Hsieh, Jenn-Jeih Hsu. Risk factors for placenta praevia in an Asian population. Int J Gynaecol Obstet. 2007;97:26-30.

7. Rabia Raheel, Rumina Tabassum, Ambreen Bhutto, Haris Riaz, Raheela Hanif. Fetal out come in cases of 
placenta praevia: a retrospective study. Med Channel. 2010 Jan;16(2):256-9.

8. Farkhunda Khursheed, Fouzia Shaikh, Chandra Madhu Das, Raheela Bilal Sheikh. Placenta praevia: an analysis of risk factors. Med Channel. 2010 Jul;16(3):417.

9. Nyango DD, Mutihir JT, Kigbu JH. Risk factors for placenta praevia in Jos, north central Nigeria. Niger J Med. 2010 Jan-Mar;19(1):46-9.

10. Surraya Halimi. Association of placenta praevia with multiparity and previous cesarean section. J Postgrad Med Inst. 2011;25(02):139-42.

11. Shabnam Naz, Rehana Parveen, Afshan Bhatti. Major placenta praevia: a true obstetric emergency. Med Channel. 2009 Jul-Sep;15(3):74-7.

12. Dong Gyu Jang, Ji Sun We, Jae Un Shin, Yun Jin Choi, Hyun Sun Ko, In Yang Park, et al. Maternal outcomes according to placental position in placental praevia. Int J Med Sci. 2011;8(5):439-44.

13. Wen S, Demissie K, Liu S, Marcoux S, Kramer MS. Placenta praevia and male sex at birth: results from a population-based study. Paediatr Perinat Epidemiol. 2000 Oct;14(4):300-11.

14. A. Ozgur Yeniel, A. Mete Ergenoglu, Ismail Mete Itil, Niyazi Askar, Reci Meseri. Effect of placenta praevia on fetal growth restriction and stillbirth. Arch Gynaecol Obstet. 2012 Aug;286(2):295-8.

DOI: $10.5455 / 2320-1770$. ijrcog20150215

Cite this article as: Meena N, Dave A, Meena S, Meena A, Shrivastava A. Impact of placenta praevia on obstetric outcome. Int J Reprod Contracept Obstet Gynecol 2015;4:76-80. 